\title{
Enfrentando dilemas: práctica de cesáreas en los últimos momentos del embarazo
}

\section{Coping with Dilemmas: Practicing Caesarean Sections during the Last Moments of Pregnancy}

\author{
Alicia Márquez Murrieta \\ (D) https://orcid.org/0000-0002-9513-5463 \\ Instituto de Investigaciones Dr. José María Luis Mora, México. \\ amarquez@institutomora.edu.mx
}

Resumen: El artículo busca aprehender las narraciones, experiencias y subjetividad de mujeres embarazadas que querían un parto fisiológico, el cual por diversas circunstancias terminó en cesárea. Mujeres mexicanas de clase media urbana, quienes también acudieron a un curso psicoprofiláctico. Interesa reflexionar sobre las decisiones y los dilemas que enfrentan en los últimos momentos del embarazo, los cuales modifican un curso de acción que habían deseado e imaginado y de qué manera les otorgan sentido. El proceso no se da en el vacío y sí en relación permanente con discursos normativos de diverso tipo, frente a los cuales las mujeres son capaces de navegar. Se trata de una primera aproximación a la temática, de corte cualitativo. El análisis a partir de las narrativas permitió aprehender la experiencia y la subjetividad que aparece en tonos crepusculares; también nos permite confirmar que algunas decisiones tomadas al inicio de los embarazos impactarán en lo que sucederá meses después.

Palabras clave: embarazo; cesárea; decisión; narración; experiencia; subjetividad.

cómo citar: Márquez Murrieta, A. (2019). Enfrentando dilemas: práctica de cesáreas en los últimos momentos del embarazo. Secuencia (104), e1751. Dor: https://doi.org/10.18234/

(c) (i) Esta obra está protegida bajo una Licencia Creative Commons Atribución-NoComer-

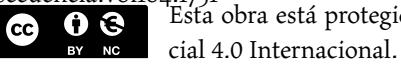


Abstract: The article seeks to record the narratives, experiences and subjectivity of pregnant women who wanted a physiological delivery, which for various reasons ended in a Cesarean section, specifically Mexican women from the urban middle class, who also attended a psycho-prophylactic course. The article seeks to reflect on the decisions and dilemmas they faced in the last moments of pregnancy, which modified a course of action they had desired and imagined and how they gave them meaning. The process does not occur in a vacuum but in a permanent relationship with normative discourses of various types, within which women are able to navigate. It is a first, qualitative approach to the subject. The narrative-based analysis made it possible to capture the experience and subjectivity that appears in twilight, while confirming that certain decisions made at the beginning of pregnancies will affect what happens months later.

Key words: pregnancy; C-section; decision; narration; experience; subjectivity.

Fecha de recepción: 8 de junio de 2018 Fecha de aceptación: 8 de marzo de 2019

\section{INTRODUCCIÓN}

$\mathrm{D}$ esde el momento en que les dan a conocer su embarazo, es común que las mujeres de clase media urbana en México acudan a un especialista. En la mayoría de los casos se trata de un ginecólogo ya conocido o por conocer quien acompaña el proceso hasta el momento del parto. Algunas mujeres y sus parejas de este grupo poblacional acuden, además, a asesorías de diverso tipo, entre ellas a los cursos psicoprofilácticos. Ambas búsquedas, sobre todo en el primer embarazo, contribuyen a estabilizar un curso de acción novedoso, imaginando un parto fisiológico (o "natural" como muchas personas lo llaman), otorgando algo de certeza y confianza a las mujeres, así como en ocasiones también a sus parejas. Pero qué sucede cuando, por algún motivo, a veces inexplicado, inesperado o urgente, el curso de acción enfrenta a las futuras madres y a sus parejas, también presentes en algunos casos, a "tomar una decisión" y aceptar la práctica de una cesárea.

Situaciones muy variadas llevan a estas intervenciones quirúrgicas: unas sin gran apremio, pero con sugerencias (o francas presiones) del cuerpo 
médico para realizarlas; otras, con un conocimiento desde el inicio del embarazo de la existencia de esa posibilidad debido a variadas condiciones de salud; otras más, actuando ante la urgencia. Frente a diversas posibilidades, como las enunciadas, u otras, ¿cómo viven las mujeres estos procesos?, ¿cómo enfrentan la modificación de un curso de acción, de sus expectativas y de qué manera les dan un nuevo sentido?, ¿necesitan dárselo?, ¿cómo acomodan y reacomodan sus vivencias, en ocasiones manteniendo sentimientos contradictorios frente a lo sucedido?, ¿cómo aprehenden la experiencia y cómo se relaciona ello con su subjetividad?

Las interrogantes y el interés por la temática surgen de una experiencia personal. Sin embargo, lo relevante de investigar el tema no se limita a ella. Se trata, en efecto, de una arista fundamental en la comprensión de los fenómenos actuales del embarazo, parto y puerperio, de su fuerte medicalización y del creciente número de cesáreas en el mundo y en México. ${ }^{1}$

$\mathrm{Al}$ revisar la literatura se encuentran trabajos que abordan de manera crítica la medicalización del embarazo y del parto, ${ }^{2}$ y cómo los procedimientos de inducción del parto y algunas prácticas que ahora son cuestionadas se han convertido en eventos patologizados; también el creciente aumento de las cesáreas innecesarias (Camacaro, 2009; Costa, Navarro, Grynszpan y Borges, 2006; Sarda, 2009). Dentro de este universo, lo que viven las mujeres de clase media urbana aparece en algunos trabajos (Cárdenas, 2014; Sánchez, 2003; Sánchez y Pérez, 2016; Schwarz, 2009 y 2012).

Existen trabajos de corte cualitativo-cuantitativo que buscan mostrar la magnitud de la situación a nivel mundial, regional y nacional sobre el aumento de las cesáreas (Editorial, 2018). Uno en particular (Betrán, Ye, Moller, Zhang, Gülmezoglu y Torloni, 2016) señala que "Considerar solamente

${ }^{1}$ Según The Lancet, las series muestran que la tasa global de nacimientos por cesárea se ha duplicado en los últimos quince años hasta llegar a $21 \%$ y que el aumento es de $4 \%$ anual. El número especial dedicado a las cesáreas, indica asimismo que la oms calcula entre 10 y $15 \%$ como máximo porcentaje para la práctica de la cesárea; por encima de esos porcentajes la oms considera que se está haciendo un uso excesivo de la misma (Editorial, 2018, p. 1279). En México "los datos para 2012 indicaban que poco más de $45 \%$ de los nacimientos fue por cesárea" (Pozzio, 2016, p. 105). No solamente se trata de un alto porcentaje; también se verifican aumentos considerables en las tasas de nacimientos por cesárea en las últimas décadas en el país.

${ }^{2}$ No todos los trabajos tienen la misma conceptualización del término "medicalización". Me inscribo en la literatura que lo aprehende en tanto proceso que antes pertenecía a otros ámbitos y que poco a poco "entra" en el campo médico y desde ese lugar es tratado (Murguía y Ordorika, 2016). El embarazo y el parto son ejemplos de este deslizamiento (véase Márquez Murrieta, 2016). 
factores médicos en este escenario complejo puede llegar a ser un esfuerzo inútil para reducir cesáreas innecesarias (unnecessary cs). Factores asociados con miedos y vidas de las mujeres y creencias culturales (cultural beliefs) están, seguramente, contribuyendo al incremento y deben ser considerados en la ecuación" (p. 9).

No afirman que sean los únicos. En sus conclusiones señalan la necesidad de hacer estudios de corte cualitativo para comprender diversas razones por las que la cesárea ha aumentado, análisis que se deberían hacer, dice el texto, tanto en el ámbito biomédico como también entre las personas y sus experiencias ante el embarazo, el parto y la cesárea.

También las posturas contrarias elaboran contraargumentos y establecen puntos sobre los cuales las controversias se desarrollan. Se trata de un campo en disputa de gran amplitud. En relación con las controversias, Sarda (2009) establece el siguiente argumento crítico: ante las crecientes investigaciones que muestran que las cesáreas están asociadas con efectos adversos en madres e hijos y ante los argumentos económicos que apoyarían la idea de reducir el aumento de dicha práctica, la profesión médica sigue sin dar prioridad a la reducción de las cesáreas.

Una de las estrategias más poderosas de esta postura en las controversias -explica Sarda- es insistir en la necesidad de realizar más investigación sobre los riesgos y beneficios de los diferentes modos de parir y, por lo tanto, dado que no se tiene una evidencia clara al respecto -continúa la argumentación-, la cesárea sería significativamente menos perjudicial que un parto vaginal. Ante esta constelación argumentativa -remata Sarda-la atención tiende a orientarse a la decisión de la madre, pero esta no es problematizada en sí, ni el papel del cuidador (caregiver) en la construcción de dicha decisión, punto fundamental que queda fuera del análisis -insiste la autora-. De esta manera -dice Sarda- la actual práctica obstétrica queda desatendida (unassailed).

Entre los discursos críticos sobre la medicalización se encuentran algunas investigaciones que indagan en las posibilidades y los beneficios de los llamados "partos humanizados"; algunos trabajos más exploran el arraigo de la práctica de las parteras profesionales y tradicionales (Basso y Monticelli, 2010; Berrio, 2014; Campiglia, 2017; Carrera, 2015; Pozzio, 2016; Pruvost, 2017).

Por otro lado, los cursos psicoprofilácticos, sus objetivos, su desarrollo y la manera como las mujeres y sus parejas los experimentan se han estudiado poco (Méndez, 2015; Sapién, 2006; Sapién y Córdoba, 2007; Sapién, Córdoba y Salquero, 2008; Tabak, 2014). 
Ambos discursos, los ginecológicos y los psicoprofilácticos, son considerados en mi investigación como de tipo experto: unos biomedicalizados, los otros "híbridos"; ambos se colocan en el nivel de la norma adecuada a seguir.

En torno a las dimensiones de seguridad, riesgo, miedo al dolor también se ha escrito y existen algunas investigaciones que muestran su enorme presencia en los discursos medicalizadores, incluso las relaciones entre estas dimensiones y la mayor patologización de los embarazos y los partos (Campos, 2010; Quattrocchi, 2014; Rocha, Franco y Baldin, 2011).

La literatura ha señalado cómo en la medicalización del embarazo y el parto, así como en el aumento del uso de tecnologías, la noción de riesgo y de dolor se encuentra muy presente. El mandato del "dolor" es casi tan importante como el del "riesgo" en los ámbitos medicalizados. Si del parto sólo se espera un dolor insoportable, resulta fácil pensar que se buscará a otra persona para aliviarlo, en este caso un experto, alguien que "sabe" lo que hace (Calafell, 2018).

En la revisión de la literatura me percaté que, si bien hay textos que abordan la maternidad, la gestación, el embarazo, pocos se concentran en las experiencias de las mujeres en los momentos cercanos al parto (Gil-Bello, 2018, sí lo hace), las dudas que enfrentan, las tensiones que viven, la manera como narran lo vivido. ${ }^{3}$ Si se considera el periodo del embarazo de forma dinámica, como un proceso en el que las percepciones y las vivencias van cambiando y que, particularmente, la cercanía del parto puede producir experiencias particulares, resulta fundamental aprehender los últimos meses del embarazo como una "transición"; lo mismo se podría decir del momento de la decisión ante una cesárea. Mi texto busca dar pistas sobre cómo se viven dichos procesos (transiciones) y cómo se reflexiona y narra sobre ellos; en particular sobre ese momento de decisión que "interrumpe" un cierto curso de acción; cómo se colocan las mujeres, a veces con sus parejas, delante de ese momento de inflexión y cómo reorganizan el sentido de lo vivido (si es que lo reorganizan), y cómo ese suceso es resignificado por las mujeres. Asimismo, de qué manera integran (o no) los discursos de los cursos psicoprofilácticos en estas experiencias y narraciones. Un tema particular es el relativo a los dis-

${ }^{3}$ La noción de narrativa tiene un lugar central en mi investigación y se vincula con la perspectiva cualitativa de la misma; para mí, remite a la idea de que las personas, a través de procesos reflexivos, otorgan sentido a sus acciones y son capaces de integrarlos en una secuencia, con cierta causalidad. Véase en Hamui (2011), un interesante análisis sobre la temática. 
cursos sobre seguridad, riesgo, miedo al dolor, nociones que encontraron un lugar importante en las narraciones de casi todas mis entrevistadas.

Sintetizando, el objetivo del texto es aprehender los sentidos, las narraciones, las experiencias y la subjetividad de las mujeres que deben tomar decisiones al final del embarazo, las cuales modifican un curso de acción que habían decidido y de qué manera le otorgan sentido. Así, en el texto me pregunto por el dilema parto fisiológico/cesárea en mujeres mexicanas de clase media urbana, el cual se va construyendo a lo largo del embarazo y encuentra su punto culminante en los momentos cercanos al parto. ${ }^{4}$ Este proceso no se da en el vacío y sí en relación permanente con discursos normativos de diverso tipo (mandatos de maternidad, del cuerpo sano, familiares, entre otros).

El periodo del embarazo-parto y los cursos de acción que toman las mujeres, entre ellos ir al ginecólogo y acudir a cursos psicoprofilácticos, ${ }^{5}$ se inscriben en una manera de ejercer la maternidad, de ser una "buena madre", pero también de cuidar el cuerpo, de seguir los mandatos sobre cuerpos saludables muy presentes en la actualidad, particularmente en el grupo poblacional que se configuró en la investigación. Es así que elegir la adecuada y capacitada persona con quién llevar a cabo la práctica del parto, así como el lugar y el cómo debe realizarse; la idea de acudir, además, a un curso psicoprofiláctico y con quién hacerlo, abonan en esos "mandatos de maternidad" y de "autocuidado", que tienen que ver con construcciones socioculturales y que podemos aprehender con la noción de "prácticas reproductivas". Es decir, no se dan en el vacío y sí tienen que ver con marcos que cuentan con características particulares, opciones, recursos e intereses específicos.

Por otro lado, los discursos normativos que atraviesan las vivencias de las mujeres, se encuentran ellos mismos en disputa y mantienen tensiones

${ }^{4}$ Una vez dictaminado anónimamente el texto, fue discutido en los seminarios Salud, Historia y Sociedad Contemporánea, y Riesgo y Medicalización en México. Agradezco a sus integrantes, así como a Graciela de Garay, Lina Berrio y Fabiola de Lachica, las críticas y comentarios que hicieron. A Cristina Sacristán, de manera particular, por la formulación de esta frase. También, a los dictaminadores anónimos. Espero haber retomado lo esencial de sus ricas y profundas sugerencias. Mención especial tienen las mujeres que compartieron conmigo sus narraciones. Gracias por la confianza. Por supuesto, la responsabilidad de lo escrito es enteramente mía.

${ }^{5}$ No son los únicos. En las narrativas de mis entrevistadas fue visible la importancia de haber recurrido a información de todo tipo: libros especializados, revistas, consultas a páginas de Internet; también, el lugar preponderante de conversaciones con madres, hermanas, amigas, suegras y con desconocidas a través de redes sociales, como Facebook. Esto también contribuye a ir formándose una vivencia del embarazo y del parto. 
sobre nociones de género; del cuerpo sano; de la biomedicina versus visiones menos medicalizadas. El paso por un embarazo y el parto enfrentan a las mujeres a dichos discursos e incluso a dimensiones de lo incierto, lo inseguro, el riesgo, el miedo al dolor.

En este navegar entre discursos las personas pueden encontrar, no sin dificultad, la brújula. Es decir, pese a estas normatividades, las personas cuentan con cierta idea, a veces más clara que otras, de lo que quieren y por qué lo quieren, idea en tensión con dichos discursos que norman la manera "correcta" de vivir un embarazo y parir.

\section{MATERNIDAD, EXPERIENCIA Y SUBJETIVIDAD}

Lo que analizo en las entrevistas tiene que ver, entre otras cosas, con nociones de maternidad. Las perspectivas actuales sobre la maternidad coinciden en que se debe problematizarla y proponer nuevas rutas desde donde entender, explicar y transformar las maternidades (Saldaña, Venegas y Davids, 2016). En su introducción al libro jA toda madre! Una mirada multidisciplinaria a las maternidades en México, estos autores afirman que debemos alejarnos de dicotomías que reducen la complejidad del campo y proponer puntos de vista analíticos que eviten universalizar la experiencia de las mujeres y la experiencia de la reproducción. También que la maternidad siempre tiene un carácter contextual y debe entendérsela como experiencia y construcción social. Para ello se requiere observar la articulación de diversas jerarquías sociales encarnadas en la experiencia materna, así como de los discursos y significados impuestos desde la cultura, manteniendo, además, una mirada multidisciplinaria (pp. 15-16).

Por otro lado, retengo la idea de que la maternidad "no se deriva de la función reproductiva de las mujeres, sino que es un proceso históricamente determinado, y como tal sus características dependen de las relaciones sociales y de las elaboraciones culturales a través de las cuales las mujeres construyen su maternidad" (Sánchez, 2003, p. 21).

Asimismo, debemos entender la maternidad asociada con una noción de género capaz de permitirnos ver los diversos significados construidos en distintos contextos y ver de qué manera dan forma y son formados por la acción, en procesos sociales e instituciones. Por ello, el género no debe ser 
aprehendido como una categoría unificada sino multifacética, diversa y negociable (Sánchez, 2003).

En las sociedades occidentales desde hace algunos siglos se produjo la "maternalización de las mujeres", en particular en las poblaciones blancas y de clase media, fenómeno que instituye una manera adecuada de ser madre, la "buena madre" que se presenta como un modelo universal, natural, necesario y capaz de definir a todas las madres en tanto se correspondería con una función biológica y social (una de las dimensiones fundamentales de los análisis de género): parir y cuidar de los hijos (Schenone, 2018, p. 49). También podríamos añadir la idea de que una "buena madre" toma decisiones adecuadas y se preocupa por su salud y la de la criatura que carga en el vientre. A través de estudios empíricos, con coordenadas precisas sociales, geográficas e históricas, se busca aprehender cómo se establecen estos rasgos generales; también, qué tensiones y negociaciones se realizan.

Son útiles dos categorías analíticas: trayectoria reproductiva y prácticas reproductivas. La primera, según Lina Berrio (2014), estaría regulada parcialmente por la cultura reproductiva; tiene que ver con una serie de procesos longitudinales asociados a la edad, conformados por transiciones cruciales en la vida de las personas; procesos que también permiten observar el modo en que las transiciones se van concatenando y van definiendo la trayectoria específica de la persona, grupo o cohorte en un periodo mayor. En la trayectoria se toman en cuenta diferentes transiciones (por ejemplo, el inicio de la vida conyugal, de la maternidad, el tipo de atención obstétrica utilizada en el embarazo y el parto, el lugar de la resolución del evento obstétrico) que pueden dar cuenta de comportamientos individuales condicionados y reglamentados socialmente y que corresponden a universos específicos, que marcan cambios en los roles, en los estatus, en el lugar social ocupado por las personas a medida que viven diversas transiciones (p. 214). Lo importante de la noción es que nos permite integrar los sucesos, las transiciones en temporalidades y procesos más largos. En este artículo, la trayectoria reproductiva y la idea de transición son útiles para pensar los últimos meses del embarazo y sobre todo el momento de la cesárea.

Para Sánchez (2003), las prácticas reproductivas, que se insertan en la trayectoria, tienen que ver con un entramado social que tejen las mujeres al ejercer su capacidad reproductiva, fenómeno que se puede dar en dos niveles: aquellas que prevalecen al interior de un mismo sector socioeconómico, por ejemplo, mujeres con similar comportamiento reproductivo y que combinan de manera peculiar la vida familiar, de pareja, sexual y laboral; y aquellas que 
tienen que ver con los caminos socioculturales o prácticas reproductivas desde que inician su vida sexual hasta que llegan al control de su vida reproductiva, la forma en que entretejen sus experiencias sexuales, reproductivas, de pareja, de maternidad y crianza. Esta noción también es útil para aprehender las prácticas del grupo poblacional que analizo.

Ahora bien, las personas no somos un mero reflejo de normatividades. La aproximación sobre sujeto de Ana Amuchástegui es útil en mi trabajo. Los sujetos -señala Amuchástegui (2018) - se desenvuelven en condiciones sociales y despliegan prácticas de salud caracterizadas por su aspecto relacional, existencial y pragmático. Tales prácticas, implican siempre encuentro y diálogo con otros, sean profesionales de la salud, familiares, o personas que viven la misma situación. El diálogo puede darse en tensión, estableciéndose entre concepciones y mandatos de cómo actuar correctamente, ante otros y con uno mismo. Un momento en donde podemos observar cómo operan las normatividades pero también como las mujeres navegan entre ellas y otorgan sentido a sus acciones es cuando deben "decidir"6 si quieren o no una cesárea y las maneras como otorgan sentido (o no) a esta decisión.

En la breve constelación conceptual que realizo falta incorporar la noción de experiencia y su relación con la subjetividad. Para Joan Scott (2001), la experiencia se configura a partir de varias narrativas que sirven para explicarla, las cuales son "inescapablemente históricas" en el sentido de ser "construcciones discursivas, de conocimiento del yo y no reflejos de una verdad interna ni externa" (p. 69). Expresado en clave sociológica, la experiencia y las narrativas a ella asociada pasa por procesos complejos de reflexividad que se encuentran ubicados en contextos históricos específicos (que deben tomarse en cuenta y estudiarse empíricamente), así sucede con las maternidades. Es en el trabajo reflexivo que se va configurando un sujeto que hace frente y acomoda (se acomoda también) a los discursos y las prácticas hegemónicas.

${ }^{6}$ Cabe preguntarse cómo sería la calidad de las decisiones en estos casos y si las mujeres conocen todas las alternativas, si siquiera las imaginan. Resulta clave la reflexión que Naila Kabeer (1999) hace sobre el poder y la decisión. Para ella se trata de relaciones estrechas entre dimensiones estructurales y decisiones individuales; la "habilidad" para tomar decisiones implica tres dimensiones: recursos (condiciones previas), agencia (proceso) y logros (lo que viene después, los resultados, la magnitud, profundidad y extensión del cambio producido por la decisión). "Al tratar de establecer si un logro tiene que ver con decisiones significativas, nos debemos preguntar si otras elecciones eran no solamente materialmente posibles, sino también qué tanto eran concebidas como siendo parte de los reinos de la posibilidad (within the realms of possibility)." (p. 442). 
Además, la experiencia nos permite entender la elaboración subjetiva de significado frente a los valores imperantes en el grupo social (Sánchez, 2003).

Por todo lo anterior, si bien es importante observar las tecnologías biomédicas, las posturas ginecológicas, los cursos psicoprofilácticos, las controversias médicas, también es fundamental aprehender la experiencia de los agentes sociales frente a ellos y las maneras que tienen de narrarlas; es decir, establecer la interrelación entre tecnologías y discursos expertos y la experiencia cotidiana de las personas (Amuchástegui, 2018). Este andar nos encamina hacia la búsqueda de la aprehensión de las complejas interrelaciones entre narración, reflexividad, experiencia y subjetividad.

\section{¿CÓMO ME ACERQUÉ A LAS ENTREVISTADAS? ASPECTOS METODOLÓGICOS}

La manera como contacté a mis entrevistadas está asociada con las redes sociales y generó algunas particularidades. Una colega, quien trabaja temáticas cercanas a las mías y a quien le platiqué mi interés de investigación y me comentó que ella pertenecía a una página en Facebook, ${ }^{7}$ con aproximadamente 10000 personas inscritas, dedicada a "dialogar" sobre temáticas y dudas en torno al embarazo, a la crianza, a la lactancia materna, me propuso realizar una publicación con los criterios que yo requería. En mayo de 2017 publicó lo siguiente:

Hola momz! Una investigadora de la UNAM [sic] está buscando mujeres que le quieran contar su experiencia para una ponencia (obvio su relato será confidencial).

Las características son:

-Que hayan estado preparándose para parto natural, a través del curso psicoprofiláctico, con la idea siempre de tenerlo por esta vía y al final, haya resultado cesárea.

${ }^{7}$ En las entrevistas conversamos sobre esta página y los usos que mis entrevistadas le han dado (así como a otras redes sociales); también sobre los beneficios que le encuentran, cómo les ha servido en momentos de inquietudes e interrogantes.

Este tipo de espacios se añaden a los que tradicionalmente han sido estudiados, lugares de socialización entre mujeres para intercambiar conocimientos, dudas, miedos, información precisa; experiencias en torno al embarazo, los partos, la lactancia materna, etc. Claudia Carrera encontró lo mismo en su investigación, 2015. 
-Que haya sido su primer parto.

-Que el curso haya sido parte del paquete del parto ofrecido por el hospital.

¡Muchas gracias por su apoyo! Creo que es una buena oportunidad para dar voz a estas experiencias que luego quedan guardadas.

Quien esté interesada yo la pongo en contacto. [Al final incluía un emoticón sonriendo. $]^{8}$

El primer vínculo lo estableció ella y seguramente coloreó la respuesta de las mujeres puesto que era miembro de esa página, con cierta historia de interacción entre ella y las otras personas que la integran. Las mujeres que decidieron responder a la publicación lo hicieron por "autoasignación", le dieron sus teléfonos, las contacté y concertamos citas entre los meses de mayo y septiembre de 2017. La última entrevista fue el 18 de septiembre de ese año, un día antes del temblor de la Ciudad de México, lo que contribuyó para que la fase de entrevistas parara abruptamente.

Hice contacto telefónico con diez mujeres, pero se concretaron seis entrevistas; entre otras causas, porque resultó difícil encontrar una fecha adecuada para conversar y porque algunas se habían mudado a otra región del país. La mayoría de las entrevistas se realizaron en cafés en los que ellas me citaron, generalmente cerca de sus hogares, o directamente en sus casas, todas en diferentes puntos de la Ciudad de México.

En el momento de mi llamada telefónica y durante la entrevista se establecía un segundo vínculo, otro momento de confianza que se tenía que tejer. Sin lugar a dudas, el primer contacto que tuvieron con mi colega, a través de la página de Facebook, se entrelazaba con mis preguntas y sus respuestas.

${ }^{8}$ Explico brevemente el porqué de los criterios: 1. Querer un parto fisiológico y buscar un curso psicoprofiláctico me permite indagar sobre dos discursos expertos con los que lidian las mujeres; 2 . Que el embarazo terminara en cesárea me parecía importante porque enfrenta a los sujetos a una decisión (más o menos "libre") y permite detectar "transiciones" y dilemas asociados a estas; 3. Un primer embarazo y parto enfrenta a las mujeres a una mayor incertidumbre que los subsecuentes (si los tiene); 4. Que el curso sea parte del paquete hospitalario puede ser una pequeña ventana para detectar, a través de las narrativas de las mujeres, tensiones, contradicciones, inconsistencias al interior del discurso especializado de los médicos y del espacio hospitalario de tipo privado. Si bien, todos los criterios fueron adecuados, considero que este último, que me sigue intrigando y pareciendo una veta importante a analizar, se tendría que indagar a través de otras vías. 
Para reflexionar acerca de la experiencia, las narrativas, la subjetividad frente a discursos normativos durante el proceso del embarazo-parto y los dilemas ante una cesárea consideré que una aproximación cualitativa era la que se requería, así como el uso de la técnica de la entrevista semiestructurada; con esta lente se pueden comprender ciertas dimensiones como la subjetividad humana, la simbolización del cuerpo, las relaciones de género, entre otras; "aparece como una forma necesaria de acercamiento cuando la perspectiva de la realidad que se busca conocer es el punto de vista de los actores, la interpretación desde la experiencia vivida" (Szasz y Amuchástegui, 1996).

\section{PERFILES SIMILARES}

Las seis mujeres tienen características sociodemográficas parecidas, lo cual quizá sea un sesgo producido por la estrategia que seguí para contactarlas. ${ }^{9} \mathrm{Al}$ grupo que se conformó se le puede denominar "de mujeres de clase media urbana".

Excepto una que el embarazo y el parto los vivió en Sidney, Australia, los demás transcurrieron en la Ciudad de México; las entrevistadas tuvieron sus embarazos entre los 30 y los 34 años de edad; sus hijos tienen actualmente (2019) entre uno y seis años aproximadamente, algunas con dos hijos (lo que permitió una doble reflexión acerca de la experiencia, pese a que a mí la que me interesaba era la narración del primer embarazo y parto).

Todas con estudios de licenciatura terminados (una con estudios de maestría), con parejas heterosexuales, la mayoría todavía en una relación de pareja y una separada del padre de su hijo. Durante las entrevistas no les pregunté sobre su situación conyugal y la relación con el embarazo, punto que puede ser importante, según lo señalan estudios que toman en cuenta la "trayectoria reproductiva"; ${ }^{10}$ sin embargo, a partir de la manera de referirse a sus parejas, me parece que todas estaban casadas. Un punto relevante al respecto de sus parejas, es que a través de las voces de las mujeres se veía su presencia constante (a veces contradictoria o en tensión) durante el embarazo y en el momento de la decisión; la mayoría acompañándolas a las citas ginecológicas y siendo parte de los cursos psicoprofilácticos; casi en todos los casos la pareja

${ }^{9}$ Habría que preguntarse si el perfil de las personas que pertenecen a esta página se orienta hacia ciertas características socioculturales y socioeconómicas.

${ }^{10}$ Véanse, por ejemplo, varios capítulos en Sánchez (2014). 
diciéndoles que la decisión era de ellas cuando se presentaron momentos de inflexión, particularmente al momento de enfrentar la decisión de la cesárea:

Él me respetó muchísimo. En todo este proceso como que me acompañaba, pero incluso a la hora de elegir hospital él me decía "pues al final la que va a entrar eres tú, la que tiene que estar confiada eres tú, tú decide y yo te respaldo, pero yo no puedo tomar una decisión por algo que es completamente tu cuerpo, tú lo vas a sentir, yo voy a ir y voy a recibir a mi bebé y te voy a acompañar a ti pero a mí no me van a inyectar, no me van a abrir”. Entonces él lo respetaba. [...] Él no necea en que lo natural... "más bien lo que a ti te haga sentir cómoda, si tú quieres un parto, espera el parto y si ya no quieres esperar el parto, ya no lo esperes". Él es muy práctico (Laura, ${ }^{11} 30$ de mayo de 2017).

Las seis entrevistadas trabajaban de manera remunerada durante el embarazo y algunas renunciaron a sus trabajos después de cierto tiempo o después del nacimiento del segundo hijo.

El costo de la hospitalización osciló entre los 80000 y los 100000 pesos, aproximadamente; parcialmente cubiertos por los seguros médicos privados, de ellas, de sus parejas o de ambos, los cuales cubrieron en promedio $60 \%$ del total del parto. Según tres de ellas, el seguro médico también hubiera cubierto el parto fisiológico, y una comentó que la única diferencia eran las noches de hospitalización que el seguro cubría. Dos de ellas gastaron muy poco debido a que fueron atendidas en servicios públicos de salud. En un caso, en México, el costo de la cesárea fue de 1500 pesos y el de la hospitalización de su hijo 250 pesos. ${ }^{12}$

Algunas de las características que resumí brevemente las sintetiza Cárdenas (2014) (quien retoma a su vez los hallazgos de diversos autores): "Las mujeres con mayor escolaridad, que residen en zonas urbanas o de mayores niveles socioeconómicos, que cuentan con mayores ingresos o con seguros médicos privados o que acuden a unidades médicas privadas corren un mayor riesgo de que alguno de sus partos sea atendido mediante esta intervención [refiriéndose a la cesárea]" (p. 115).

${ }^{11}$ Todos los nombres de las entrevistadas fueron cambiados. Guardé solamente la primera letra de su nombre.

${ }^{12}$ El recién nacido tuvo que quedarse unos días en el hospital para observación. 


\section{ENTRE GINECÓLOGOS Y PSICOPROFILÁCTICOS: EL EMBARAZO EN LO COTIDIANO}

Varias de las maneras en que las mujeres entrevistadas vivieron el embarazo y el parto, así como el grupo poblacional que emergió (clase media urbana), se acercan a lo encontrando en otras investigaciones en México y otros países como Argentina (Sánchez, 2003; Sánchez y Pérez, 2016; Schwartz, 2009 y 2012).

Ante la noticia del embarazo se piensa un camino a seguir, se navega en mares coloreados por la trayectoria reproductiva; estos primeros pasos, estas prácticas reproductivas pueden tener un mayor o menor impacto en los momentos cercanos al parto y en las decisiones que se deberán tomar (transiciones muy importantes dentro de la trayectoria reproductiva).

El proceso del embarazo-parto que se integra en la trayectoria con prácticas reproductivas específicas se percibe en mis entrevistadas. ${ }^{13}$ En cuanto supieron que estaban embarazadas, algunas enfatizaban que había sido un embarazo buscado, otras que no era buscado pero sí deseado, otras que simplemente supieron que estaban embarazadas, acudieron con ginecólogos ya conocidos o recién recomendados; tuvieron un seguimiento constante y accedieron a diferentes tecnologías reproductivas, las cuales estuvieron más presentes conforme se acercaba el momento del parto. Las mujeres describían lo que habían vivido con detalles técnicos, con lenguaje, categorías y terminología médica muy precisa. Una de las tecnologías - presente en todas mis entrevistadas-fue el ultrasonido, realizado cada mes en algunos casos. Varias de mis entrevistadas, debido a condiciones de salud previas -como la diabetes o el hipotiroidismo- fueron monitoreadas, incluso cada dos días, durante las últimas semanas del embarazo. ${ }^{14}$

${ }^{13}$ Una aclaración. Mi investigación no se centró en la narración del posparto y de la lactancia. Sin embargo, llama la atención el peso que tiene la lactancia en las narraciones de mis entrevistadas, así como las tensiones y ambivalencias que produce la experiencia de amamantar y su relación con los mandatos de la "buena madre". Con respecto a este punto, algunas mantenían una postura crítica frente a los cursos psicoprofilácticos y a la importancia e insistencia sobre la leche materna.

También se observan, en las narraciones, tensiones acerca de la nueva organización del tiempo y la repartición de tareas a partir de la llegada de un hijo o hija al hogar.

${ }^{14}$ Las prácticas reproductivas de las mujeres de ingresos medios de la investigación de Sánchez (2003) tienen mucho en común con lo encontrado en mi investigación: vivieron el embarazo y el nacimiento con muchas exigencias, "como tareas a desempeñar exitosamente" y para ello se auxiliaron de especialistas (libros, artículos, psicólogos, técnicos y médicos); prestaron gran atención a sus cuerpos, por ejemplo, llevando un seguimiento mensual del embarazo. 
Cinco de las mujeres se atendieron con ginecólogos (cuatro mujeres y un hombre) y una con matrona (en Sidney, Australia). ${ }^{15}$ Cuatro (Laura, Gisela, Inés y Dulce) tuvieron sus cesáreas en hospitales privados, dos en un hospital ubicado al oeste de la ciudad, conocido por su apoyo a los partos fisiológicos, y las otras dos, en un hospital con dos sedes, en Tlalpan-Sur y en la colonia Roma-Sur; ${ }^{16}$ otras dos mujeres (Irma y Lorena) se atendieron, una, en instalaciones del sector público de salud de Australia y la otra en una institución pública de salud en México (Hospital General del Sistema Nacional de Salud, de alta especialidad).

Con respecto a asesorías de otro tipo, y en particular a los llamados cursos "psicoprofilácticos", las seis mujeres acudieron a ellos (no todos se llamaban de esa manera: por ejemplo, uno se llamaba "Curso para nuevos padres"). En cuatro casos el curso psicoprofiláctico estuvo asociado al hospital (Inés, Dulce, Irma y Lorena). En dos de ellos (Inés y Dulce) los cursos estuvieron incluidos en el paquete hospitalario $y$, de hecho, en esos casos, la presencia del curso psicoprofiláctico en el "paquete" fue una de las razones para elegir el hospital. Una de ellas, Inés, embarazada en el momento de la entrevista, se encontraba haciendo todo para poder tener un parto fisiológico en su segundo embarazo. ${ }^{17}$ Las otras dos mujeres, Irma y Lorena, cuyos cursos estaban asociados a los hospitales, pero no inscritos en algún paquete, eran las de los hospitales públicos, en Australia y México.

En contados hospitales públicos en México existe la posibilidad de tener un curso psicoprofiláctico. Hasta el momento conozco el de mi entrevistada (Hospital General Dr. Manuel Gea González, en Tlalpan, al sur de la Ciudad de México) y uno que detecté en la literatura, el Hospital Regional $1^{\circ}$ de Octubre del Issste, ubicado en la zona norte metropolitana (Sapién, 2006).

Se hicieron varios estudios, llevaron dietas balanceadas y tomaron cursos para adquirir información y conocimientos; estas mujeres intentaron tener sus partos con el método psicoprofiláctico y buscaron controlar el miedo y el dolor (p. 219).

${ }^{15}$ Dudé si incorporar la experiencia de Irma en mi investigación. Dado que se trata por el momento de una aproximación a las narrativas de las mujeres ante la cesárea, decidí dejarla pese a ser una experiencia geográfica e institucional muy distante y diferente.

${ }^{16}$ Los costos y el tipo de hospital en donde se lleva a cabo la práctica tienen que ver con una reflexión muy importante en la literatura acerca de las desigualdades y la estratificación en el campo de la salud materna y en el acceso a la salud. Véase Freyermuth (2014).

${ }^{17} \mathrm{Su}$ segunda hija ya nació. No he podido volver a entrevistarla pero me comentó por mensaje que nació también por cesárea. 
Parece existir una relación entre las características socioeconómicas, culturales y geográficas de las entrevistadas y querer un parto "natural", fisiológico, así como la búsqueda de otro tipo de asesoría; parece darse asimismo una relación entre estas elecciones y la trayectoria reproductiva de personas cercanas como madres y hermanas $;^{18}$ asimismo, las diversas redes de pertenencia desempeñan un papel importante (consejos de amistades, familiares menos cercanos, suegras, compañeras de trabajo). De manera particular, la transmisión de experiencias por parte de madres a hijas, incluso la propia manera de venir al mundo apareció en mis entrevistas. Por ejemplo, en varias se narra con precisión cuánto tiempo y cuántos centímetros de dilatación tenían sus mamás al nacer ellas. En la narrativa de Inés queda clara la relación entre el psicoprofiláctico y la familia:

Es un tema muy familiar, toda mi familia, todas mis tías han sido parto psicoprofiláctico, todas mis primas, bueno no todas, hay unas que sí han tenido cesárea, pero todas ¡siempre han sido así, como pro-parto! ¡Todo natural! Todo es como muy de mi familia, muy de mi mamá. Mi mamá estuvo igual, o sea los tres fuimos partos naturales psicoprofilácticos, y pues yo también (Inés, 2 de junio de 2017).

Después de este breve resumen de los dos caminos, desarrollo a continuación con más detalle cada uno, sin olvidar que en este artículo son aprehendidos ambos como discursos expertos, maneras en las que se manifiestan normatividades y formas de "lograr" ser una buena madre y "tener" un buen cuidado de sí misma y del bebé.

\section{El camino biomédico: atenderse con un ginecólogo durante el embarazo}

La decisión de con quién hacer el seguimiento del embarazo puede desempeñar un papel relevante para lo que ocurrirá meses después. ${ }^{19}$ La relación de los ginecólogos y los hospitales, así como los equipos con los que trabajan puede

${ }^{18}$ El peso de dichas opiniones y sugerencias y la orientación que pueden dar a las decisiones es enfatizado en diversas investigaciones. Véase por ejemplo el trabajo de Carrera (2015).

${ }^{19}$ Existe un trabajo muy interesante en México, el cual "documenta experiencias y percepciones de mujeres que atendieron su embarazo y parto en distintos modelos de atención”, Freyermuth (2015). Cursivas mías. 
orientar e influir sobre ciertas prácticas. En las narraciones de las entrevistadas se percibía la relación entre ginecólogos y equipos de trabajo, así como cierta organización del espacio en relación con las prácticas ginecológicas. ${ }^{20}$ Cárdenas (2014) afirma que el tipo de institución donde los doctores ejercen su trabajo puede afectar la frecuencia en el empleo de la cesárea.

Fueron con ginecólogos que ya conocían porque las atendían de tiempo atrás; en el camino, algunas buscaron nuevas opciones. En dos casos, la decisión de con quién atenderse tuvo que ver con el sistema de salud: en Australia, Irma se hubiera atendido con las matronas en turno de los Servicios Públicos de Salud, pero al entrar a un programa piloto, fue durante todo el embarazo con una matrona que le asignaron (lo mismo sucedió en su segundo embarazo). En el caso de Lorena, la decisión tuvo que ver con su salud y la ginecóloga pertenecía a un hospital público; fue la que le asignaron dadas sus características de diabetes e hipotiroidismo.

\section{La elección del curso psicoprofiláctico y el para qué}

Se puede datar a finales de los años cincuenta la llegada del método psicoprofiláctico ${ }^{21}$ a México, traído por Stefanovich y la doctora Stoopen. Fue en el Hospital Central Militar que se hicieron las primeras prácticas por Santibáñez Moreno y Fuentes Calvo; los médicos Manuel Mateos Cándano y Graciela Orgay dieron al método psicoprofiláctico un carácter más médico e intervencionista (Sapién, 2006, p. 25). En el sistema de salud público tuvo momentos importantes de expansión, profesionalización e institucionalización entre 1959, 1971, 1975, hasta llegar al Hospital Regional $1^{\circ}$ de Octubre del Issste en donde el doctor Sergio Villalobos, jefe de los Servicios de Ginecología y Obstetricia, inauguró en 1981 el Servicio de Psicoprofilaxis Perinatal (Sapién, 2006, pp. 25-26).

${ }^{20}$ En el artículo me enfoco en las mujeres y sus narrativas sobre lo vivido y no abordo la relación con los contextos materiales, tecnológicos, los insumos y los espacios en donde las prácticas se llevan a cabo; dimensión importante que queda pendiente para otras reflexiones y trabajos. Véase Campiglia (2017), en especial el apartado titulado "La cesárea como icono de la permeabilidad del MMH a la lógica de mercado".

${ }^{21}$ Me detengo brevemente en la historia de los cursos psicoprofilácticos para explicar algunas particularidades, por ejemplo, incluir en su temario "los cuidados del bebé" (lo que no aparece en sus inicios, ni se observa en otros países). 
Entre las principales razones por las que esta práctica sería benéfica se encontrarían las siguientes: evitar problemas en el parto porque los cursos permitirían que estos procesos se desarrollaran con mayor facilidad; los cursos tienen el objetivo de dar a la mujer embrazada conocimientos y actitudes físicas adecuadas para enfrentar este momento (por ejemplo, le enseñan a confiar en las habilidades de su cuerpo para entender y participar activamente en el trabajo de parto y en el nacimiento); el conocimiento de lo que va a pasar y va a sentir; el entrenamiento en las técnicas para manejar el dolor y responder a él propiciarían cambios en la mujer; los cursos, al involucrar a la pareja, contribuirían a que ambos, hombre y mujer, se hagan responsables del embarazo y se hagan cargo del nacimiento (Sepién, 2006, p. 27).

Sapién (2006) observó los cursos en la investigación que realizó y sintetiza los contenidos más destacados: rutina de ejercicios de fisioterapia obstétrica, relajación corporal y mental, técnicas de ventilación, posición de decúbito lateral izquierdo, extensión abdominal, simulacro de trabajo de parto, simulacro de expulsión, examen antes del trabajo de parto, preparación de la ida al hospital para el parto, explicación de la rutina hospitalaria para y durante el parto, consejos sobre cómo atender al recién nacido, acompañamiento a la embarazada en tocología, lactancia materna a libre demanda, cuidados y recomendaciones para mantener la salud en el embarazo (pp. 47-51).

La oferta privada de estos cursos en México es muy variada y extensa, como ejemplo tenemos la Asociación Nacional de Instructoras en Psicoprofilaxis Perinatal (ANIPP). Asimismo se cuenta con una gran variedad de técnicas y cursos, como el referido por una entrevistada "el hipnoparto"; la incorporación de parteras profesionales y tradicionales, o el trabajo de doulas, etcétera.

Algunos de los cursos de tipo psicoprofiláctico se ofrecen en los hospitales privados, incluso, en algunas ocasiones pueden estar incluidos en los "paquetes" de parto, como señalé al reseñar las opciones elegidas por algunas de mis entrevistadas.

Comparando, en los cursos privados y públicos (sólo en dos casos) $)^{22}$ elegidos por mis entrevistadas, la secuencia de actividades referida por Sa-

${ }^{22}$ En el caso de Irma, prácticamente no hubo narración sobre el curso porque le pareció muy malo. Sin embargo, se enfocó mucho en los cursos posparto y la utilidad que tuvieron para ella. La importancia de estos, señalaba, era enorme en contextos de poca o nula ayuda doméstica (como en Australia) y para que las mujeres socializaran su experiencia. 
pién es prácticamente idéntica. Además, las mujeres entrevistadas pusieron énfasis en que el psicoprofiláctico sí las había preparado para el parto y que contribuyó a enseñarles cómo detectar las señales de que el parto se aproximaba; también les ayudó a saber relajarse, visualizar lo que iba a pasar, reducir su miedo y su estrés; la presencia y acompañamiento de la pareja que propiciaba el psicoprofiláctico fue un rasgo que cinco de ellas resaltaron (Irma, no mencionó nada al respecto); aprehender cómo cuidar al bebé al llegar a casa fue fundamental y algunas técnicas de lactancia materna.

Una razón para asistir al curso, mencionada de una $u$ otra forma por todas las entrevistadas, era la búsqueda por manejar el dolor durante el parto. Algunas le llamaron "miedo al dolor". Varias de las entrevistadas manifestaron su ansiedad, su miedo al dolor, el no saber qué ocurriría, la falta de control; para algunas el psicoprofiláctico fue muy útil para reducir estas sensaciones, sin embargo, en un caso estos cursos le generaron más miedo.

Realizo una breve síntesis de sus narraciones. La primera entrevistada, Laura, fue a un curso pequeño, en una colonia al norte de la ciudad, cercano a donde sus padres viven. Fue a ese curso porque su hermana se lo recomendó; en el segundo embarazo fue a un curso de hipnoparto. Con su primer hijo, buscó un psicoprofiláctico en cuanto supo que estaba embarazada. Le pareció un buen curso, la instructora insistía en la capacidad de parir de las mujeres pero también daba su lugar al saber médico. La entrevistada señala que el curso "iba muy bien" con ella y su marido, y su forma de pensar, porque impulsaba el parto pero también eran respetuosas de las personas que preferían cesáreas y colocaban en su justa dimensión a los gineco-obstetras; por ejemplo, dice que insistían en que si había alguna complicación médica "no se aferraran". También mencionó mucho durante la entrevista el mensaje que les transmitían en el curso acerca del cuerpo de las mujeres, de cómo estamos hechas para parir y de la animalidad de las personas.

Gisela fue a un lugar especializado en partos "naturales" y llegó a él vía Internet; como ya estaba muy adelantado el embarazo, asistió a pocas sesiones. Acudió ante la falta de información por parte de la ginecóloga que daba seguimiento a su embarazo. El curso le sirvió para conocer otras experiencias y para la comunicación con su pareja; sin embargo, le parecía que a las instructoras les faltaba información. El curso, en lugar de quitarle miedos, contribuyó a aumentarlos, sobre todo con respecto a los riesgos en la salud: "Un tema que ellas daban era el de cómo era el embarazo, dónde se gestaba, cuáles eran los riesgos de salud. Una vez durante los temas fuertes nos pusieron un 
video de un parto extremo y yo decía 'bueno, con esto no me dan ganas para nada de tener un parto'. Además, era como un video muy viejo. Manejaban mucho la administración del dolor" (Gisela, 30 de mayo de 2017).

Las instructoras le parecieron demasiado "proparto" y "antiginecólogos" y "anticesáreas". Considera que a su ginecóloga no le encantaba que fuera, lo toleraba pero cuando había intromisiones de ese campo en el suyo, se molestaba.

La tercera, Inés, fue al incluido en el paquete del hospital donde tendría el parto. Ella quiso un curso psicoprofiláctico porque es un tema muy familiar, dijo, al menos de su familia porque la de su esposo es más de la idea de no sufrir, sobre todo en el siglo xxI. Al estar incluido en el paquete del hospital no buscó otro. La sesión que más le interesaba era sobre el manejo del dolor en el parto: "me interesaba justo en la parte del manejo del dolor y el curso tenía unas clases buenas, interesantes [...]. Me acuerdo que cuando fue la clase del dolor se me hizo buenísima y dije 'esto es lo que me va a ayudar en el parto"' (Inés, 2 de junio de 2017).

La ginecóloga de Inés toleraba poco el psicoprofiláctico. De hecho le dijo que en el gremio se llamaba el "circoprofiláctico" porque, le decía: "llegan muy valientes y luego ya te piden la epidural". En su segundo embarazo fue a otro que le parece mucho más especializado y profesional (quiere un lugar que apoye claramente el trabajo de parto); de hecho, de ahí salió la recomendación para el ginecólogo con el que se estaba atendiendo el segundo embarazo y la recomendación para la doula que la acompañaría durante el nacimiento de su segunda hija.

La cuarta entrevistada, Dulce, también asistió al curso incluido en el paquete del hospital, recomendado por una tía. Durante la entrevista comentó varias veces que ella y su esposo eran bastante escépticos, sin embargo, le sirvió sobre todo para tener una gran seguridad con el bebé una vez en casa. A su doctor le parecía bien que asistiera, sobre todo si con eso ella estaba tranquila y relajada, pero también le pedía que si había un conflicto de opiniones, diera peso a la suya, particularmente ante las varias amenazas de aborto y de parto prematuro que vivió durante el embarazo. Durante la entrevista criticó mucho a las instructoras del curso por tener una postura tan "antigineco-obstetras". Afirmaba que hasta les daba miedo, a ella y a su marido, decirles que ellos no tenían problema si el embarazo terminaba en cesárea.

Irma habla del "curso para nuevos padres" a partir de los siete meses, el cual es parte del sistema de salud en Australia; con un costo bajo, no es obligatorio pero lo recomiendan. Ella no tiene una buena impresión del curso; lo 
que aprendió, lo hizo a través de libros y nadando con las matronas (en ese espacio de socialización conoció muchas más cosas, me dijo).

Lorena estaba muy entusiasmada por el curso. Le dio mucha tranquilidad sentirse informada: "pero te das cuenta que por más informada que estés, es como un mundo súper desconocido, entras a un mundo que no controlas, que nadie controla" (Lorena, 18 de septiembre de 2017).

Lo expresado por las mujeres se acerca a lo detectado en un estudio en Guatemala. Las mujeres de la investigación en Guatemala manifestaron que el curso les ayudó a conocer acerca de las respiraciones, a mantener el control psicológico durante el trabajo de parto, también les ayudó a sentirse más tranquilas y con menos miedo. Algunas mujeres consideraron que la priscoprofilaxis previene algunas complicaciones durante el trabajo de parto (Méndez, 2015), punto no mencionado por mis entrevistadas. Cabe aclarar que en ese país, a partir de lo que aparece en el trabajo referido, no integran la temática del cuidado del bebé, ni el de la lactancia materna.

En este rápido recorrido por las experiencias de mis entrevistadas se observa cómo los expertos de uno y otro campo (ginecólogos e instructoras de los cursos psicoprofilácticos) tienen imágenes y posturas sobre el otro campo, incluso francas críticas.

Las mujeres navegan entre esas opiniones, a las que se suman las de familiares y amistades, lo que puede servir o llegar a producir tensiones, dudas, incertidumbres o hasta malestares.

\section{MOMENTOS DE DECISIÓN}

En todas las narraciones se detecta la importancia de la confianza, de la buena comunicación e información, así como del respeto y la escucha en la relación entre las mujeres, a veces su pareja, y sus ginecólogos. Parece darse un vínculo estrecho entre querer algo (parir de manera "natural", fisiológica) y sentir ser tomada en cuenta y escuchada. Al analizar las entrevistas, observo que algunas de estas mujeres, en algunas ocasiones, no percibieron esa escucha, sino informaciones y actitudes no muy claras por parte de sus doctores (incluso también en los cursos psicoprofilácticos). Hay un caso, Inés, en donde la confianza parece haberse roto; la entrevistada habla incluso de engaño.

¿De qué manera estos sentimientos y percepciones contribuyen a la manera como se procesó posteriormente la experiencia de la cesárea y a la 
manera como se la integró en la subjetividad? Es un aspecto fundamental que debemos indagar con mayor profundidad.

Todas las entrevistadas dicen haber querido un parto fisiológico desde un principio. Algunos estudios muestran que las mujeres nulíparas tienen disposición a hacer frente a complicaciones obstétricas antes de solicitar una cesárea electiva (Cárdenas, 2014).

En las seis entrevistadas, ¿cuáles fueron las razones médicas para la práctica de la cesárea narradas por ellas? Laura tuvo su cesárea en la semana 42 porque el niño no bajaba y en su segundo embarazo en la semana 39 con cinco días y ante una presión alta que no cedía; Gisela, en la semana 37 también porque no había bajado el bebé y no se presentaban contracciones; la tercera, Inés, en la semana 40, estuvo con contracciones durante muchas horas pero no dilataba más allá de tres centímetros.

La cuarta, Dulce, tuvo su hijo en la semana 34 y cinco días (tuvo un embarazo muy difícil con varias amenazas de aborto y de parto prematuro); empezó el trabajo de parto con contracciones que le parecían raras "nada más las contracciones juna sensación rarísima! Y yo decía... no sé, no te puedo decir qué sentía, pero yo decía jesto no está bien!" (Dulce, 5 de junio de 2017). Iba a ser parto fisiológico y fue cesárea porque en el trabajo de parto el bebé movió su brazo y se atoró, el doctor trató de moverlo pero no pudo y ella ya no dilataba más.

Irma tuvo la cesárea en la semana 41 (en Sidney, Australia), empezó teniendo un parto fisiológico, pero no dilataba después de varias horas de trabajo de parto. En su segundo parto, pidió cesárea porque "sabía" que sucedería lo mismo.

Lorena es diabética y tiene hipotiroidismo, lo que no le impedía tener un parto fisiológico, pero su hijo tenía que nacer en la semana 38. Lorena enfatiza que muy pronto supo que era un embarazo de "alto riesgo" y nombra a la diabetes y al hipotiroidismo como sus dos "enfermedades". En la semana 38 fue a inducción del parto pero se dieron cuenta que el niño se había volteado de nuevo y venía podálico: "A mí me citan, yo no iba a cesárea, yo iba a una inducción de parto [...] porque, aparte él, ya se había volteado, entonces todo era para inducir parto natural, pero tenía que ser esa semana, no se podía pasar" (Lorena, 18 de septiembre de 2017). Con la inducción y las contracciones el bebé empezó a tener sufrimiento fetal y tuvieron que realizarle una cesárea de emergencia.

Llama la atención la precisión de la información que me dieron estas mujeres, aún años después de haber tenido a sus hijos: recuerdan con mucha 
exactitud el peso, la talla; narran con gran detalle la sucesión de hechos hasta llegar a la cesárea. También, es importante resaltar el énfasis que hacían (y el que hacen muchas mujeres al narrar sus partos) en la dilatación y en los centímetros que se logró avanzar por hora, así como en los estancamientos.

\section{¿Y CÓMO SE DA SENTIDO A LO OCURRIDO?}

En mis entrevistadas, y a partir de la narración que hicieron, parecería que en tres casos la cesárea fue necesaria y se realizó ante momentos de emergencia (Dulce, Irma y Lorena); en el caso de Laura, si bien, no aparece como una emergencia, la cesárea se percibe como una decisión acorde con las circunstancias; en el caso de Gisela queda la duda acerca de la necesidad de la intervención quirúrgica; un caso genera muchas dudas e Inés así lo expresa:

Desde la semana 29 siempre estuvo abajo, digamos que siempre estuvo en posición pero no se encajaba. Entonces sólo me decían eso, que no se encajaba, pero no me explicaban nada. Por ejemplo, te puedo decir ahora, en mi segundo embarazo qué es el borramiento, en ese momento solamente me decían "¡uy, yo creo que no se va a borrar tu cuello!" Pero yo ni siquiera entendía a que se referían con eso. [...] Lo que me dijeron, ya acercándose la fecha, cuando yo tenía casi treinta y nueve semanas, fui [con la ginecóloga] y me dijo "jel sábado vas a tener casi cuarenta!" Yo el lunes cumplía cuarenta semanas. Entonces, lo que ella quería era inducirme jel sábado!, o sea dos días antes. Me dijo "iqué te parece si te vienes, te inducimos y ya? [ponerle oxcitocina, práctica muy generalizada en México y hoy fuertemente cuestionada]. Y si no se puede, pues ya termina en cesárea, pero te inducimos porque ya vas a estar a dos días, ya estás lista". O sea, como toda doctora te decía "es que no hay que correr riesgos, porque si te empiezas a pasar (de eso sí me acuerdo muy bien) la placenta se puede calcificar y bueno, o sea, como que se empieza a complicar mucho si te pasas de la cuarenta" (Inés, 2 de junio de 2017).

Además de las dudas que aparecen en el extracto de entrevista, vemos que se usa la noción de riesgo, que es enunciada por la ginecóloga. La presencia de discursos de seguridad, de riesgo, de dolor en el campo médico y sobre todo en momentos cercanos al parto coincide con los hallazgos de varias investigaciones (Campos, 2010; Rocha, Franco y Baldin, 2011; Quattrocchi, 2014). 
Un curso "normal" de acción, que fue interrumpido por la cesárea (una transición), ¿de qué manera es reflexionado por estas mujeres? Laura estaba segura de que su ginecóloga había sido respetuosa de su búsqueda proparto hasta los límites de la seguridad. ${ }^{23}$ Está segura que tomaron la mejor decisión y narraba que había vivido todo con tranquilidad, aunque varias veces en la entrevista repitió la frase "sí siento que me quedé a deber mi parto".

En mi caso, de mi hijo que mi doctora dijo "ya no"... y sí, a lo mejor me pude haber esperado tres días más... iy si le pasaba algo?...Yo estoy tranquila con esta decisión. Sí siento que me quedé a deber mi parto pero en términos de salud siento que fue la mejor decisión que pudimos haber tomado, que ya mi niño no tenía que estar allá adentro. Y siento que si por mi necedad le hubiera pasado algo, entonces sí no te lo perdonas. Creo que sí es importante, es que no sé cómo decirlo... quitarle el estigma a la cesárea. No pasa nada, tampoco tienes que tener un parto si no quieres. Para mí es lo mismo un aborto, una cesárea, un parto, es tu decisión, tú decides cómo traer a tus hijos al mundo o decides no traerlos al mundo, es una decisión personal (Laura, 30 de mayo de 2017).

Gisela no está muy segura de la postura de la ginecóloga, considera que fue buena doctora para ella porque hizo un seguimiento adecuado de su hipotiroidismo y su embarazo, pero no le daba información que ella le pedía y fue ese el motivo para acudir a los cursos psicoprofilácticos:

Como yo vi que no me decía nada, pues yo decía que parecía que me estaba atendiendo una tos, como si no tuviera molestias. jPero yo tenía mucho miedo porque para mí era la incertidumbre total! Me dije, "no tengo embarazadas cercanas" [...] No tenía como que el entorno. Entonces, le dije [a su pareja], "pues vamos con alguien, sé que hay cursos y sé que van los dos papás, entonces está muy bueno para nosotros” (Gisela, 30 de mayo de 2017).

Gisela no está molesta porque todo salió bien, además, con su pareja se pusieron rápido de acuerdo. En su narrativa aparece varias veces la idea del miedo:

${ }^{23}$ Tuvo un segundo embarazo y también quería un parto fisiológico, el cual también concluyó con una cesárea, con la misma ginecóloga. 
No nos tomó mucho tiempo [se refiere a su pareja], realmente como hemos sido instruidos pues en esa área [se refería al seguimiento estrecho de doctores y en hospitales], no pasa nada. Entre mi miedo del dolor como que escondido y entre que, en verdad, te juro, no tenía contracciones [...] fue en una consulta que la doctora dijo "aquí hay de dos sopas: te lo inducimos o cesárea ¿qué quieres? No va a ser natural porque no tienes contracciones [...]”. La pregunta se la contestamos en el siguiente minuto, o sea, no había nada que pensar (Gisela, 30 de mayo de 2017).

La tercera, Inés, la más crítica de todas ante la cesárea y la actitud de la ginecóloga, piensa que su ginecóloga no era proparto, "si leí cuáles son las señales de que tu doctor no es proparto y en mi caso ella sí las tenía, bueno, y las tuvo. ¡Definitivamente no es una ginecóloga proparto!” (Inés, 2 de junio de 2017). Inés es a quien percibí con más sentimientos encontrados al narrar lo sucedido. No cambió de doctor porque no lo tenía tan claro en ese momento y porque sentía que la traicionaría, ya que era su ginecóloga desde hacía muchos años. Ella no parece convencida de que fuera necesaria la cesárea y varias veces en la entrevista repitió que no se había informado y preparado lo suficiente, pareciendo cargar con la responsabilidad de la cesárea y atribuir a su falta de preparación el hecho de haber llegado a una.

La cuarta, Dulce, está convencida que su ginecólogo fue muy respetuoso y que hubiera tenido un parto de no haber sido un embarazo tan complicado pero, sobre todo, que hicieron lo posible para lograr el parto fisiológico. Considera que su cesárea fue absolutamente necesaria. Dulce afirma categóricamente que en un siguiente embarazo tendría cesárea: "Hoy, si yo tuviera otro hijo programaría la cesárea desde el minuto número uno, para nuevamente tener una cesárea. No tiene nada de malo, pero la gente no es como uno" (Dulce, 5 de junio de 2017).

Irma acudió con su matrona cada mes. Hacia el final del embarazo empezaron a intervenir también médicos porque el niño no nacía. Cuando se rompió la fuente, vieron meconio pero en Australia - dice la entrevistada- no lo toman como un dato alarmante o estresante. Sí hubo un poco de sufrimiento fetal. El momento del parto fue de emergencia. Ella tiene total claridad que la cesárea era necesaria. De hecho, en su opinión, insistieron demasiado en el parto fisiológico. En su segundo embarazo pidió la cesárea desde un inicio, lo que en Australia, en el servicio público de salud no era habitual, según Irma, más bien se deja llegar a la mujer embarazada hasta la semana 39 y es a partir 
de ese momento que se vislumbra la posibilidad de la intervención quirúrgica, si antes no se ven complicaciones, me explicó. Pero ella sabía que el parto terminaría en cesárea:

Me metieron al quirófano y la matrona me dijo "ya écheselo natural, lo puede hacer". Yo le dije "no, no va a ser natural, va a ser cesárea". Me preguntó por qué y le dije que tenía muchas razones pero principalmente porque sé que esto va a terminar en cesárea, instinto [...] levantan a [nombre de su hijo] y tenía [...] un (true nut) un nudo así [hace un gesto con su mano para mostrar un nudo], $100 \%$ nudo, que al momento de nacer natural se iba a estrangular y le iba a cortar..., o sea iba a terminar en cesárea de emergencia otra vez jde todas formas! [...]. Entonces, en el momento en que la matrona recibe a [nombre del niño], me voltea a ver, se disculpa y me dice "tenías razón, iba a terminar en cesárea" (Irma, 24 de agosto de 2017).

Lorena confía plenamente en el trabajo de su ginecóloga en el Hospital de Alta Especialidad. En cuanto se enteró de su embarazo y dadas sus "enfermedades" y el seguimiento que ya le hacían en el Instituto Nacional de Nutrición, la canalizaron. Ella y su pareja decidieron ir al Gea González y ya ahí le asignaron a la jefa de Ginecoobstetricia de la institución. Está muy contenta con el seguimiento que le dieron. Iba cada quince días y al final cada dos; era "una chambota" -dice-: "La ginecóloga me quiso porque vio el compromiso que teníamos con el embarazo". Afirmó tener una confianza total con la doctora: "Nunca buscamos [se refiere a buscar segundas opiniones]. La verdad es que yo soy como de la idea de que hay que confiar en el doctor, si a él le vas a otorgar tu vida y la de tu bebé, lo que dijera, yo lo hacía y nunca buscamos otras opciones [...] Nunca lo cuestionamos [la posibilidad de la cesárea], si llegamos a la semana 38 y él no ha nacido, va a ser cesárea" (Lorena, 18 de septiembre de 2017).

Está convencida que fue una cesárea necesaria.

En este recorrido se pueden percibir las maneras cómo las mujeres, muchas en diálogo con sus parejas, reconstruyen la decisión y establecen el grado de necesidad de la cesárea, con dudas, inflexiones, tensiones, sentimientos de culpa o de reivindicación. La reflexión a posteriori de lo ocurrido les da una mayor o menor certeza y confianza. Estoy convencida que dicha capacidad reflexiva también se dio a partir de su decisión de responder a la publicación en Facebook y en el momento mismo de la entrevista, en el diálogo que sostuvimos. 
Durante la entrevista conversamos sobre el hecho de haberse sentido interpeladas por la publicación y de los porqué habían decidido responder, primero a mi colega y después a mí la solicitud de entrevista y a narrarme su experiencia. Hago una rápida síntesis: contestar a la convocatoria y contarme lo que vivieron fue importante en el marco de una reivindicación actual por "lo natural" y de crítica a las cesáreas, es decir, que querían exponer la idea de que algunas sí son necesarias y que algunos ginecólogos buscan auténticamente llevar a la mujer a un parto (sobre todo lo enfatizaban Laura y Dulce). En este mismo sentido, también ellas dos enfatizaban que no se es mejor o peor mamá si se tiene una cesárea por necesidad o por elección. En un sentido diferente, Inés, quien fue la más crítica en su narrativa con respecto a lo vivido, señaló: "a la fecha me pregunto si mi cesárea era necesaria o no".

Para todas es importante compartir lo que vivieron porque hay muchos mitos y poca información y es un tema sobre el que se habla poco; consideran que su experiencia algún día podría ayudar a otra mujer a comprender lo que vives.

También, dos de ellas (Irma y Lorena) mencionaron el término de violencia obstétrica, que yo no introduje en ningún momento en la entrevista, no para referirse a su experiencia pero sí porque saben de la temática y les parece muy importante documentar más casos y tener más información sobre lo que sucede:

Creo que sí es importante hacerlo público. Una, porque mi experiencia es diferente a la de muchas en México; porque es real el hecho de la depresión posparto [tema que no fue mencionado por mí en la entrevista]; también es real que una cesárea es un atropello a tu cuerpo, pero que muchas veces no es que quieran, sino que es necesario. Pero yo sí considero que en México hay muchas. Una buena investigación formal es necesaria para que mucha gente se dé cuenta de que realmente lo estamos haciendo mal y no es realmente mal porque sí, es muchas veces por creencia ¿cómo podemos mejorar algo? (Irma, 24 de agosto de 2017).

\section{REFLEXIONES CONCLUSIVAS}

Las seis narraciones sintetizadas en el artículo hacen aparecer diferentes escenarios: en algunos casos la cesárea parece necesaria, en otros existen dudas y en otros más parece lo más adecuado. 
En la indagación sí parece confirmarse que las mujeres llegan al embarazo con ciertos conocimientos y muchos consejos y que la presencia de las redes de adscripción desempeñan un papel central en los caminos que se recorrerán; también, que la decisión sobre el camino a seguir, tomada desde el inicio del embarazo, orienta lo que ocurrirá meses después.

Por otro lado, en el trayecto hacia el parto en los primeros embarazos, y sobre todo los momentos cercanos al parto y las decisiones orientadas a él, pueden vivirse con incertidumbre y dudas. Es decir, mucho de lo aprendido resulta poco útil para lo que se está viviendo por primera vez. Prácticamente todas las entrevistadas dejaron ver estas dudas y reflexionaban, unas más que otras, sobre el poco control que se tiene y lo desconocido de lo que viene.

Como se pudo apreciar en el artículo, en estos contextos, los discursos expertos, tanto los que provienen de la biomedicina, como los que provienen de la psicoprofilaxis (también los discursos transmitidos por familiares y pares -las diversas redes de adscripción y socialización-) son útiles. Sin embargo, también pueden producir una especie de cacofonía cuando no son claros, son contradictorios o no respetan las diferencias. En algunas ocasiones esta multitud de discursos silencian o distorsionan la voz de las mujeres; en otras, sus voces logran abrirse paso, manifestarse y ser escuchadas, por la propia mujer y por los otros, de maneras tenues o fuertes.

Las mujeres, su voz y decisión están en una relación de tensión ante nociones de normalidad, de riesgo, concepciones sobre el dolor, ante mandatos sobre el ser buena madre y el autocuidarse. En este contexto, la posibilidad de tener opciones "materialmente posibles y que sean parte "del reino de la posibilidad" (Kabeer, 1999), sobre las cuales decidir, se vuelve fundamental.

La información, la confianza y la escucha atenta y respetuosa emergen en las narrativas aquí analizadas. Parece existir una relación estrecha entre estas dimensiones y la manera como las mujeres tienen experiencias que enriquecen y transforman su subjetividad. Es así que la sensación de tener poco espacio para poder explicar en detalle lo que ocurre, lo que sienten, las dudas que tienen, así como no conocer y poder analizar las opciones disponibles, aparece como una faceta clave en estos procesos, a la cual debe prestársele mayor atención.

El primer acercamiento a la temática indica que la mayoría de las mujeres (incluso sus parejas) perciben lo ocurrido en tonos grises. Utilizando el término de Clark (2005) considero que las narraciones nos hablan de momentos crepusculares (twilight moments) con respecto a lo vivido (y no de vivencias 
en blanco y negro), a la decisión de la cesárea y la manera cómo les fue presentada tal opción, al mayor o menor espacio que tuvieron para reflexionar sobre ella. En dos casos las tonalidades serían quizá un poco más tendentes a lo oscuro: en Inés se vislumbra un cierto grado de desazón que se abre camino de manera tímida entre las palabras y los gestos; en Laura, pese a percibirse su convencimiento sobre lo necesario de su cesárea, repitió varias veces en la entrevista que su parto algo le había quedado a deber.

No se puede afirmar que existió una sola manera de atravesar la experiencia, de recomponer los sentidos de la acción y procesar subjetivamente lo vivido. Las narraciones y la manera como se va dando la experiencia otorgan la posibilidad para que estas mujeres puedan elaborar subjetivamente significados sobre la maternidad, encontrar la tonalidad adecuada para pensarse frente a lo vivido y ajustar diversos discursos normativos a sus vidas.

\section{LISTA DE REFERENCIAS}

Amuchástegui, A. (2018). Mi medicamento es mi mejor amigo. Mujeres, viH y tratamiento antirretroviral en México: una relación pastoral. En A. Amuchástegui (ed.), Mujeres y viH en México: tensiones y perspectivas sobre atención a la salud. México: Salud Problema/UAM-Xochimilco/Imagia.

Betrán, A. P., Ye, J., Moller, A. B., Zhang, J., Gülmezoglu, A. M. y Torloni, M. R. (2016). The increasing trend in caesarean section rates: Global, regional and national estimates: 1990-2014. PLoS One, 11(2): e0148343. DoI: 10.1371/journal. pone. 0148343

Basso, J. F. y Monticelli, M. (mayo-junio, 2010). Las expectativas de participación de mujeres embarazadas y sus acompañantes para realizar un parto humanizado. Revista Latinoamericana Enfermagen, 18(3). Recuperado de http://www.scielo.br/ pdf/rlae/v18n3/es_14.pdf

Berrio, L. (2014). Trayectorias reproductivas y prácticas de atención a la salud materna entre mujeres indígenas de la Costa Chica de Guerrero. En A. Sánchez (coord.), Desigualdades en la procreación. Trayectorias reproductivas, atención obstétrica y morbimortalidad materna en México (pp. 211-243). México: UAM/Itaca.

Calafell, N. (2018). Del parirás con dolor hacia el parto respetado. Recuperado de https://diariocronica.com.ar/539387-nuria-calafell-sala-del-pariras-con-dolor-hacia-el-parto-respetado.html 
Camacaro, M. (2009). Patologizando lo natural, naturalizando lo patológico... Improntas de la praxis obstétrica. Revista Venezolana de Estudios de la Mujer, 14(32), 147-162. Recuperado de http://repositorio.gire.org.mx/handle/123456789/2183

Campiglia, M. (2017). La institucionalización del nacimiento. Un vínculo roto. (Tesis de doctorado inédita). CIESAs, México.

Campos, M. E. (2010). Manejo del dolor durante el trabajo de parto en gestantes de un centro de salud. Revista Cuidarte, 1(1), 35-43. Recuperado de http://www.scielo. org.co/pdf/cuid/v1n1/v1n1a06.pdf

Cárdenas, R. (2014). El perfil de utilización de la cesárea en México y su implicación para la salud reproductiva. En A. Sánchez (coord.), Desigualdades en la procreación. Trayectorias reproductivas, atención obstétrica y morbimortalidad materna en México (pp. 105-129). México: UAM/Itaca.

Carrera, C. (2015). Nuestros cuerpos, nuestros partos: apropiación subjetiva de derecho en la atención humanizada del parto en el D.F. (Tesis de maestría). UAM-Xochimilco, México.

Clark, A. (2005). Twilight moments. Journal of the History of Sexuality, 14(1/2), 139-160. DOI: $10.1353 /$ sex.2006.0007

Costa, T., Navarro, E., Grynszpan, D., Borges, M. do C. (2006). Naturalization and medicalization of the female body: social control through reproduction. Interface, 10(20). DOI: $10.1590 /$ S1414-32832006000200007

Editorial (2018). Steming the global caesarean section epidemic. The Lancet, 392(10155), 1279. DOI: 10.1016/S0140-6736(18)32394-8

Freyermuth, G. (2014). Mortalidad materna en México. Inequidad institucional y desigualdad entre mujeres. En A. Sánchez (coord.), Desigualdades en la procreación. Trayectorias reproductivas, atención obstétrica y morbimortalidad materna en México (pp. 21-70). México: UAM/Itaca.

Freyermuth, G. (coord.) (2015) La partería en México desde el punto de vista de las usuarias. Asesoría, Capacitación y Asistencia en Salud, A. C./ciesAs. Recuperado de https://parteria-omm-ciesas.org/investigaciones

Gil-Bello, R. M. (2018). El imaginario de la maternidad durante el embarazo. Matronas. Prof., 19(1), 4-10. Recuperado de https://www.federacion-matronas.org/matronas-profesion/sumarios/el-imaginario-de-la-maternidad-durante-el-embarazo/

Hamui, L. (2011). Las narrativas del padecer: una ventana a la realidad social. Cuicuilco, 52, 51-70. Recuperado de http://www.scielo.org.mx/scielo.php?script=sci_abstract\&pid=S0185-16592011000300005\&lng=en\&nrm=iso

Kabeer, N. (1999). Resources, agency, achievements: Reflextions on the measurement of women's empowerment. Development and Change, 30, 435-464. 
Márquez Murrieta, A. (2016). El maltrato de las mujeres embarazadas en los servicios de salud: un fenómeno en proceso de categorización y estabilización. En A. Murguía y T. Ordorika (coords.), La medicina en expansión. Acercamientos a la medicalización en México (pp. 117-141). México: DGAPA-UnAM.

Méndez, M. R. (2015). Psicoprofilaxis y complicaciones en el trabajo de parto. (Tesis de licenciatura inédita). Facultad de Humanidades-Universidad Rafael Landivar, Guatemala.

Murguía, A. y Ordorika, T. (coords.) (2016). La medicina en expansión. Acercamientos a la medicalización en México. México: DGAPA-UnAm.

Pozzio, M. R. (2016). La gineco-obstetricia en México: entre el "parto humanizado" y la violencia obstétrica. Estudios Feministas, 24(1), 101-117. DoI: http://dx.doi.org/10.1590/1805-9584-2016v24n1p101

Pruvost, G. (2017). Naissance respectée et polyphonie (éco)féministe. Postfacio. En A. Apfel, Donner naissance. Doulas, sabes-femmes et justice reproductive (pp. 177-206). París: Éditions Cambourakis.

Quattrocchi, P. (2014). "Riesgo" y "seguridad" durante el embarazo y el parto: desde la visión biomédica hacia la visión de las mujeres que optan por un parto domiciliar. Ponencia presentada en XIII Congreso de Antropología de la Federación de Asociaciones de Antropología del Estado Español. Periferias, Fronteras y Diálogos. Tarragona, España.

Rocha, R. da, Franco, S. C. y Baldin, N. (2011). El dolor y el protagonismo de la mujer en el parto. Revista Brasileira de Anestesiología, 61(3), 204-210.

Saldaña, A., Venegas, L., Davids, T. (coords.) (2016). ¡A toda madre! Una mirada multidisciplinaria a las maternidades en México. México: Itaca.

Sánchez, Á. (2003). Mujeres, maternidad y cambio. Prácticas reproductivas y experiencias maternas en la Ciudad de México. México: unAm/UAM-X.

Sánchez, Á. (coord.) (2014). Desigualdades en la procreación. Trayectorias reproductivas, atención obstétrica y morbimortalidad materna en México. México: UAM/Itaca.

Sánchez, A. y Pérez, F. (2016). La práctica de las cesáreas en unidades médicas privadas de Monterrey: un mercado para la salud obstétrica. En A. Saldaña, L. Venegas y T. Davids, (coords.), ¡A toda madre! Una mirada multidisciplinaria a las maternidades en México (pp. 145-174). México: Itaca.

Sapién, J. S. (2006). Prácticas y representaciones sobre sexualidad y reproducción en varones en psicoprofilaxis perinatal. (Tesis de doctorado, inédita). ENAH, México.

Sapién, J. S. y Córdoba, D. I. (2007). Psicoprofilaxis perinatal: preparación corporal y psíquica de la mujer embarazada para el nacimiento. Psicología y Salud, 17(2), 219-228. 
Sapién, J. S., Córdoba, D. I. y Salquero, M. A. (2008). Cuidado psicoprofiláctico del embarazo: experiencias de mujeres y hombres. Psicologia \& Sociedade, 20(3), 434-443.

Sarda, G. (2009). Artificially maintained scientific controversies, the construction of maternal choice and caesarean section rates. Social Theory \& Health, 9(2). DoI: http://dx.doi.org/10.2139/ssrn.1592792

Schenone, D. (2018). Las experiencias de madres feministas en las instituciones de educación superior en la Ciudad de México. En N. Baca, S. García, Z. Ronzón y R. P. Hernández (coords.), Maternidades y no maternidades. Modelos, prácticas y significancias en mujeres y espacios diversos (pp. 41-68). México: Gedisa.

Scott, J. (2001). Experiencia. La Ventana, 13, 42-73.

Schwartz, P. K. N. (2009). La maternidad tomada. Ginecólogos, obstetras y mujeres en interacción. Discursos y prácticas en la clase media. Argumentos. Revista de Crítica Social, 11, 1-26. Recuperado de https://dialnet.unirioja.es/servlet/articulo?codigo $=3993135$

Schwartz, P. K. N. (2012). Experiencias y significados del dolor durante el parto en mujeres jóvenes de sectores socioculturales medios y bajos de la ciudad de Buenos Aires. Ponencia presentada en el I Encuentro Latinoamericano de Investigadores sobre Cuerpos y Corporalidades en las Culturas, Rosario, Argentina.

Szasz, I. y Amuchástegui, A. (1996). La formación en metodología cualitativa. Perspectiva del Programa de Salud Reproductiva y Sociedad. En I. Szasz y S. Lerner, Para comprender la subjetividad. Investigación cualitativa en salud reproductiva y sexualidad (pp. 9-15). México: El Colegio de México.

Tabak, G. (2014). Corporalidades transformadas: embarazo, parto y puerperio. Ponencia presentada en la VIII Jornadas de Sociología de la UNLP, Ensenada, México. 